\title{
FORMULASI DAN PENENTUAN NILAI SUN PROTECTION FACTOR (SPF) SEDIAAN KRIM TABIR SURYA EKSTRAK ETANOL BEKATUL PADI BERAS MERAH (Oryza sativa $\mathrm{L}$ )
}

\author{
Wira Noviana Suhery ${ }^{1 *}$,Novita Dewi ${ }^{1}$, Rahayu Utami ${ }^{1}$, Mustika Furi ${ }^{1}$, Melzi Octaviani ${ }^{1}$ \\ ${ }^{1 *}$ Sekolah Tinggi Ilmu Farmasi Riau; Jalan Kamboja, Pekanbaru, Kode Pos 28289 \\ e-mail: wiranoviana@stifar-riau.ac.id
}

\begin{abstract}
ABSTRAK
Penelitian mengenai formulasi sediaan krim tabir surya dari ekstrak etanol bekatul padi beras merah (Oryza sativa L) dan penentuan nilai SPF secara in vitro menggunakan spektofotometer UV telah dilakukan. Ekstrak etanol bekatul padi beras merah telah terbukti mempunyai aktivitas antioksidan. Penentuan nilai SPF perlu dilakukan untuk mengetahui kemampuan ekstrak etanol bekatul padi beras merah dalam melindungi kulit dari radiasi sinar UV. Ekstrak etanol bekatul padi beras merah diformulasi dalam bentuk sediaan krim tipe m/a yang terdiri dari F1 dan F2 menggunakan konsentrasi ekstrak masing-masing 5\% dan 10\%. Berdasarkan penelitian yang dilakukan diperoleh hasil F2 memiliki nilai SPF yang lebih tinggi yaitu 13,098 dibandingkan F1 yaitu 11,861. Berdasarkan nilai SPF yang dihasilkan dari formula dapat disimpulkan bahwa sediaan krim tabir surya ekstrak etanol bekatul padi beras merah dapat melindungi kulit dari radiasi sinar UV secara maksimal selama 110-130 menit.
\end{abstract}

Kata kunci: Bekatul, Beras Merah, Krim, SPF, Kulit

\begin{abstract}
Study of formulation of sunscreen cream with ethanolic extract of red rice bran (Oryza sativa $\mathrm{L}$ ) and determining the SPF value in vitro using a UV spectrophotometer has been carried out. Ethanol extract of red rice bran has been shown antioxidant activity. Determining the SPF value due to determine the ability of the red rice bran ethanol extract to protect the skin from UV radiation. Ethanol extract of red rice bran was formulated in the form of a cream type o/w of F1 and F2 containing extract concentrations of 5\% and 10\%, respectively. Based on the research conducted, it was found that F2 had a higher SPF value of 13,098 than F1 of 11,861. Based on the SPF value generated from the formula, this study showed that the sunscreen cream preparation of red rice bran extract can protect the skin from UV radiation maximally for 110-130 minutes.
\end{abstract}

Keywords: Bran, Red Rice, Cream, SPF, Skin

\section{PENDAHULUAN}

Bekatul merupakan hasil samping proses penggilingan padi bagian terluar dari bagian bulir dengan kandungan serat pangan yang tinggi dan antioksidan alami. Hasil penelitian menunjukkan bahwa bekatul mengandung komponen bioaktif atau senyawa fitokimia yang tinggi seperti tokoferol, tokotrienol, oryzanol (Chen dan Bergman, 2005). Kandungan oryzanol dalam bentuk gamma oryzanol pada bekatul adalah 1,1-2,6\% (Hadipernata, 2007). Gamma oryzanol sebagai antioksidan alami umumnya merupakan senyawa fenolik atau polifenol yang berupa golongan flavonoid, terpenoid, turunan asam sinamat, tokoferol dan asam-asam organik polifungsional (Sarastani et al, 2002).

Bekatul padi beras merah memiliki aktivitas antioksidan yang tinggi karena selain adanya kandungan gamma oryzanol, adanya pigmen merah (antosianin) dan senyawa flavonoid yang tinggi pada bekatul menyebabkan bekatul padi beras merah memiliki aktivitas antioksidan yang lebih tinggi dibandingkan dengan bekatul padi beras putih (Adzkiya, 2011). Pada pengujian aktivitas antioksidan terhadap ekstrak etanol bekatul padi beras merah (Oryza sativa L) diperoleh nilai $\mathrm{IC}_{50}$ sebesar $43,2349 \mathrm{ppm}$ (Suhery et al 2016). Menurut Molyneux (2004), nilai $\mathrm{IC}_{50}$ dari 50-100 ppm termasuk dalam kategori antioksidan kuat. Berdasarkan penelitian Black (2009), antioksidan memiliki potensi sebagai fotoprotektor dan senyawa dengan kemampuan antioksidan atau penangkap radikal bebas dapat berkompetisi dengan molekul target dan mengurangi efek yang merugikan oleh radiasi sinar UV.

Nilai Sun Protection Factor (SPF) digunakan sebagai pengukuran kuantitatif dari keefektifan formulasi tabir surya untuk bisa efektif dalam mencegah kerusakan kulit yang disebabkan oleh radiasi sinar UV (Adi dan Zulkarnain, 2015). Antioksidan dapat menjadi faktor peningkatan nilai SPF karena aktivitasnya yang dapat memperlambat atau mencegah terjadinya erythema pada kulit yang disebabkan oleh radiasi sinar UV B (Wood dan Murphy, 2000). Berdasarkan penelitian Damogalad (2013), semakin tinggi konsentrasi ekstrak yang memiliki aktivitas antioksidan digunakan, maka nilai SPF akan semakin tinggi. Penelitian tentang antioksidan bekatul telah banyak 
dilakukan namun belum ada literatur yang menunjukkan nilai SPF dari ekstrak etanol bekatul padi beras merah.

Berdasarkan latar belakang diatas, penulis tertarik untuk melakukan penelitian mengenai formulasi sediaan krim tabir surya ekstrak etanol bekatul padi beras merah (Oryza sativa L) dan penentuan nilai SPF secara in vitro. Tujuan penelitian ini adalah untuk memformulasi sediaan krim tabir surya dari ekstrak etanol bekatul padi beras merah (Oryza sativa L) dan menentukan nilai SPF secara in vitro.

\section{METODE PENELITIAN}

\section{Alat dan Bahan}

Alat yang digunakan dalam penelitian adalah timbangan analitik (Shimadzu, Jepang), pH meter (Hanna, Indonesia), Spektrofotometer UV-Visible (Shimadzu, Jepang), Autoclaf, dan alat-alat gelas yang biasa digunakan di laboratorium.

Bahan yang digunakan pada penelitian ini adalah Bekatul padi beras merah (Kampung Rempak, Kecamatan Sabak Auh, Kabupaten Siak), $\mathrm{HCl}$ pekat (Merck), etanol 96\% (Brataco), emulgid, oleum sesami, gliserin (Brataco), trietanolamin (Brataco), natrium tetraborat (Brataco), dan air suling.

\section{Prosedur}

\section{Pembuatan ekstrak etanol bekatul padi beras merah}

Bekatul beras merah yang telah diayak (500 g) dimasukkan ke dalam autoklaf pada suhu $121^{\circ} \mathrm{C}$ selama 3 menit, kemudian dilanjutkan dengan pengeringan menggunakan oven pada suhu $100^{\circ} \mathrm{C}$ selama 1 jam. Sampel dimasukkan ke dalam botol kaca gelap kemudian ditambahkan etanol $96 \%$ dan $\mathrm{HCl} 37 \%$ hingga $\mathrm{pH}$ 1. Sampel dimaserasi selama 30 jam kemudian disaring. Filtrat yang diperoleh dipekatkan menggunakan rotary evaporator untuk mendapatkan ekstrak bekatul beras merah (Suhery et al, 2017).

\section{Pemeriksaan ekstrak etanol bekatul padi beras merah}

Pemeriksaan ekstrak etanol bekatul padi beras merah (Oryza sativa L) meliputi organoleptis, kelarutan (titrasi dengan pelarut), pemeriksaan $\mathrm{pH}$ dan uji flavonoid.

\section{Formulasi basis krim}

Cara pembuatan untuk basis krim :

Bahan-bahan yang terdapat dalam formula dipisahkan dalam dua kelompok, yaitu fase minyak dan fase air. Fase minyak (emulgid, oleum sesami, gliserin) dan fase air (trietanolamin, natrium tetraborat, air suling). Setiap fase dipanaskan pada suhu $60^{\circ} \mathrm{C}-70^{\circ} \mathrm{C} \mathrm{di}$ tangas air. Fase minyak dipindahkan ke dalam lumpang panas dan ditambahkan fase air gerus sampai homogen sampai dingin hingga terbentuk massa krim. Basis krim (FB) yang sudah jadi ditimbang sebanyak yang diperlukan. Di masukkan ke dalam wadah bermulut lebar dan tertutup rapat.

Tabel 1. Formula basis krim (FB) tipe m/a (Ditjen POM, 1985).

\begin{tabular}{clc}
\hline No & \multicolumn{1}{c}{ Bahan } & Jumlah (\%) \\
\hline 1 & Emulgid & 15 \\
\hline 2 & Oleum sesame & 15 \\
\hline 3 & Gliserin & 5 \\
\hline 4 & Trietanolamin & 2 \\
\hline 5 & Natrium tetraborat & 0,2 \\
\hline 6 & Air suling & $\mathrm{ad} 100$ \\
\hline
\end{tabular}

Formulasi sediaan krim tabir surya ekstrak etanol bekatul padi beras merah (Oryza sativa $\mathrm{L}$ )

Tabel 2. Formulasi Sediaan Krim Tabir Surya Ekstrak Etanol Bekatul Padi Beras Merah

\begin{tabular}{llccc}
\hline \multirow{2}{*}{ No } & \multirow{2}{*}{ Bahan } & \multicolumn{3}{c}{ Formula (\%) } \\
\cline { 3 - 5 } & & FB & F1 & F2 \\
\hline 1 & Ekstrak bekatul & 0 & 5 & 10 \\
\hline 2 & Basis krim ad & 100 & 100 & 100 \\
\hline
\end{tabular}

Cara pembuatan

Formula F1 dan F2 dibuat dengan cara basis krim yang ditimbang sebanyak yang diperlukan, kemudian ditambahkan ekstrak masing-masing sebanyak 5\% dan $10 \%$ yang sebelumnya telah dilarutkan dengan etanol 2 ml. Kemudian dimasukkan sedikit demi sedikit ke dalam basis krim, kemudian gerus homogen. Dimasukkan ke dalam wadah bermulut lebar dan bertutup rapat.

Evaluasi basis krim dan sediaan krim tabir surya ekstrak etanol bekatul padi beras merah (Oryza sativa $\mathbf{L}$ )

Uji organoleptis

Uji organoleptis meliputi bentuk, warna, dan bau.

\section{Pemeriksaan Homogenitas}

Sediaan ditimbang 0,1 gram, kemudian dioleskan pada sekeping kaca yang transparan, harus menunjukkan susunan yang homogen dan tidak boleh terlihat adanya bintik-bintik partikel (Voigt, 1994).

\section{Pemeriksaan $\mathrm{pH}$}

Pemeriksaan $\mathrm{pH}$ dilakukan terhadap 1 gram basis krim dan sediaan krim tabir surya ekstrak etanol bekatul padi beras merah yang telah diencerkan dengan air 10 
ml. Pengukuran $\mathrm{pH}$ menggunakan $\mathrm{pH}$ meter yang telah dikalibrasi sebelumnya menggunakan larutan standar pH 4 dan larutan standar 7.

\section{Pemeriksaan Daya Tercuci Krim}

Sediaan ditimbang 1 gram, kemudian sediaan dioleskan pada telapak tangan, kemudian dicuci dengan sejumlah volume air sambil membilas tangan. Air dilewatkan dari buret dengan perlahan-lahan, kemudian diamati secara visual ada atau tidaknya krim yang tersisa pada telapak tangan. Lalu dicatat volume air yang digunakan (Jellinek dan Stephan, 1970).

\section{Uji Daya Menyebar}

Sediaan ditimbang 0,5 gram, kemudian diletakkan dengan hati-hati diatas kertas grafik yang dilapisi kaca transparan. Sediaan dibiarkan sesaat (15 detik) kemudian ditutup lagi dengan lempengan kaca yang diberi beban tertentu ( $1 \mathrm{~g}, 2 \mathrm{~g}, 5 \mathrm{~g}$ ) dan dibiarkan selama 60 detik. Kemudian luas yang diberikan oleh sediaan dihitung (Voigt, 1994)

\section{Uji Iritasi Kulit}

Sediaan ditimbang 0,1 gram, kemudian dioleskan pada kulit lengan bagian dalam kemudian ditutupi dengan kain kasa dan plester. Setelah itu dilihat gejala yang ditimbulkan setelah 24 jam pemakaian. Uji iritasi ini dilakukan pada 6 orang panelis selama tiga hari berturut-turut (Ditjen POM, 1985)

\section{Pemeriksaan Stabilitas Fisik}

\section{Suhu Kamar dan Suhu Dingin}

Sediaan ditimbang sebanyak 10 gram, dimasukkan ke dalam wadah krim, kemudian sediaan disimpan masing-masing pada suhu kamar dan suhu dingin $\left(4^{\circ} \mathrm{C}\right)$. Setelah itu diamati apakah terjadi perubahan bentuk, warna, dan bau, serta terjadi pemisahan atau tidak. Pengamatan dilakukan selama 8 minggu.

Uji Nilai SPF Basis krim, Sediaan krim ekstrak etanol bekatul padi beras merah (Oryza sativa $\mathrm{L}$ )

Basis krim (FB), sediaan krim ekstrak etanol bekatul padi beras merah (F1 dan F2) masing-masing ditimbang sebanyak 0,1 gram kemudian dimasukkan ke dalam labu takar $10 \mathrm{ml}$ (10.000 ppm), dilarutkan dengan etanol 96\%. Pengenceran dibuat dari larutan induk untuk masing-masing sediaan yang digunakan. Pengenceran pertama dari larutan induk dengan pemipetan $0,5 \mathrm{ml}$ dan dimasukkan di labu takar $10 \mathrm{ml}$ (500 ppm), dilarutkan dengan etanol sampai mencapai volume tanda batas pada labu takar. Pengenceran kedua dengan pemipetan 1,0 $\mathrm{ml}$ dan dimasukkan dalam labu takar $10 \mathrm{ml}$ (1000 ppm), dilarutkan dengan etanol sampai tanda batas labu takar. Etanol digunakan sebagai blangko. Diukur serapannya dengan spektrofotometer $\mathrm{UV}-\mathrm{V}$ is tiap $5 \mathrm{~nm}$ pada rentang panjang gelombang dari $290 \mathrm{~nm}$ sampai panjang gelombang $320 \mathrm{~nm}$, diikuti dengan aplikasi persamaan Mansur (Mansur et al, 1986). Kemudian ditetapkan serapan rata- ratanya dengan interval $5 \mathrm{~nm}$. Hasil absorbansi masing-masing formula krim dicatat dan kemudian nilai SPF dihitung (Adi dan Zulkarnain, 2015). Nilai SPF dianalisis menggunakan metode (Mansur et al, 1986).

$$
S P F=C F \times \sum_{290}^{320} E E(\lambda) \times I(\lambda) \times \operatorname{Abs}(\lambda)
$$

Keterangan :

$\mathrm{CF} \quad=$ Faktor koreksi bernilai 10

$\mathrm{EE}(\lambda)=$ Efek eritmogenik radiasi pada panjang gelombang

$\mathrm{I}(\lambda) \quad=$ Spektrum simulasi sinar surya

$\operatorname{Abs}(\lambda)=$ Nilai absorbansi pada panjang gelombang

Nilai EE X I adalah konstan yang ditunjukkan pada Tabel 5 (Mansur et al, 1986).

Cara perhitungan :

Nilai serapan yang diperoleh dikalikan dengan nilai EE x I untuk masing-masing panjang gelombang. Hasil perkalian serapan dan EE x I dijumlahkan. Hasil penjumlahan kemudian dikalikan dengan faktor koreksi yang nilainya 10 untuk mendapatkan nilai SPF.

\section{Analisis Data}

Analisis data secara deskriptif menggunakan tabel dan grafik untuk mengetahui perbedaan nilai SPF pada sediaan krim tabir surya terhadap konsentrasi ekstrak etanol bekatul padi beras merah yang digunakan.

\section{HASIL DAN PEMBAHASAN}

Sebelum dilakukan proses ekstraksi sampel, terlebih dahulu dilakukan proses stabilisasi. Stabilisasi dilakukan untuk menghilangkan sifat bekatul yang tidak menguntungkan yaitu mudah tengik, karena asam lemak dalam bekatul meningkat selama proses penyimpanan. Stabilisasi dilakukan menggunakan autoclaf pada suhu $121^{\circ}$ selama 3 menit dan dilanjutkan dengan pengeringan menggunakan oven (pemanas) pada suhu $100^{\circ}$ selama 1 jam. Tujuan proses ini adalah untuk mendeaktivasi enzim lipase. Aktivitas enzim lipase yang intensif dalam bekatul mengakibatkan bekatul berbau tengik selama penyimpanan.

Ekstraksi sampel dilakukan dengan cara maserasi dengan menggunakan pelarut etanol yang diasamkan hingga $\mathrm{pH} 1$ dengan penambahan $\mathrm{HCl}$. Tujuan dari penambahan $\mathrm{HCl}$ yaitu karena $\mathrm{HCl}$ mampu mendestruksi sel tumbuhan sehingga senyawa antioksidan yang terdapat dalam sel dapat terekstrak dengan baik dan bekatul stabil pada kondisi asam dibandingkan kondisi basa, pada kondisi asam menunjukan aktivitas antioksidan yang tinggi (Widarta, 2014). Keuntungan dari metode ekstraksi dengan maserasi adalah zat berkhasiat yang termolabil tidak rusak, metode dan alat yang digunakan sederhana. 
Pelarut yang digunakan adalah etanol, karena mampu menarik semua senyawa yang ada pada sampel, murah, tidak toksik, dan aman digunakan dalam formulasi sediaan krim. Maserat yang didapatkan dari proses maserasi kemudian dipekatkan dengan rotary evaporator dan didapatkan ekstrak kental bekatul padi beras merah.

Hasil pemeriksaan ekstrak menunjukkan ekstrak berbentuk kental, memiliki bau khas dengan warna merah kecoklatan. Pemeriksaan $\mathrm{pH}$ ekstrak didapatkan pH 5 yang menunjukkan bahwa ekstrak tergolong asam karena kandungan kimia dari bekatul padi beras merah bersifat asam yaitu flavonoid. Uji kelarutan menunjukkan bahwa ekstrak etanol bekatul padi beras merah mudah larut dalam alkohol dan praktis tidak larut dalam air. Hasil pemeriksaan ekstrak disajikan pada Gambar 1 dan Tabel 3.

Penggunaan konsentrasi ekstrak etanol bekatul padi beras merah di dalam formula dipilih berdasarkan orientasi pengujian nilai SPF dengan spektrofotometer UV yang dilakukan sebelum formulasi sediaan krim. Pada formula F1 mengandung ekstrak 5\% dan formula F2 mengandung ekstrak $10 \%$. Tujuan adanya variasi konsentrasi pada formula sediaan krim adalah untuk mendapatkan sediaan krim tabir surya yang memiliki nilai SPF yang tinggi, yang memenuhi kriteria tingkat kemampuannya sebagai tabir surya.

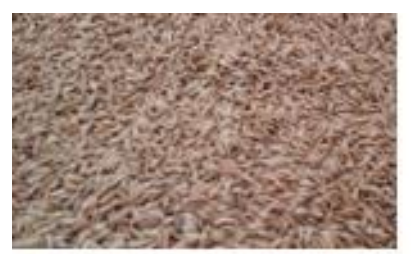

(a)

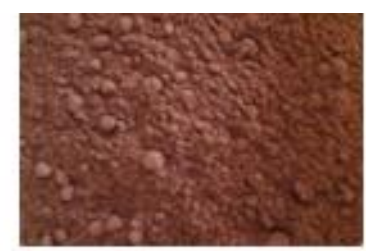

(b)

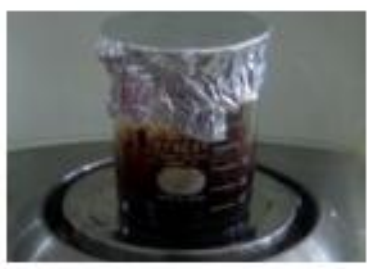

(c)

Gambar 1. (a) Padi beras merah, (b) Bekatul padi beras merah), (c) Ekstrak etanol bekatul padi beras merah

Evaluasi FB, F1 dan F2 meliputi organoleptis, homogenitas, $\mathrm{pH}$, daya cuci, daya menyebar, uji iritasi, dan stabilitas fisik suhu kamar dan suhu dingin. Hasil organoleptis menunjukkan FB, F1 dan F2 memiliki warna masing-masing putih, coklat muda dan coklat tua. Homogen, stabil terhadap suhu kamar maupun suhu pendinginan, tidak mengiritasi dan memiliki $\mathrm{pH}$ yang masuk range $\mathrm{pH}$ kulit yaitu berkisar antara 5,2-6,5 yang mana range $\mathrm{pH}$ kulit normal yaitu 4,5-7 (Wasitaamadja, 1997) berbentuk semi padat, putih, bau khas dan tidak mengalami perubahan selama 8 minggu penyimpanan (Tabel 4).

Tabel 3. Hasil Pemeriksaan Ekstrak Etanol Bekatul Padi Beras Merah (Oryza sativa $\mathrm{L}$ )

\begin{tabular}{ll}
\hline \multicolumn{1}{c}{ Pemeriksaan } & \multicolumn{1}{c}{ Hasil Pengamatan } \\
\hline Bentuk & Ekstrak kental \\
\hline Warna & Merah kecoklatan \\
\hline Bau & Bau khas \\
\hline $\mathrm{pH}$ & 5 (asam) \\
\hline Kelarutan : Air & $\begin{array}{l}\text { Praktis tidak larut (10 mg } \\
\text { dalam }>100 \mathrm{ml})\end{array}$ \\
\hline & Larut (100 mg dalam 2,0 \\
& Elanol \\
\hline Uji Flavonoid (Logam & $\begin{array}{l}\text { Positif flavonoid (terjadi } \\
\left.\text { wg }+ \text { HCl }_{\text {pekat }}\right)\end{array}$ \\
\hline
\end{tabular}

Evaluasi uji daya tercuci dilakukan bertujuan untuk mengetahui berapa banyak air yang digunakan untuk membersihkan sediaan krim tabir surya. Berdasarkan hasil daya tercuci sediaan krim yang dilakukan menunjukkan bahwa FB membutuhkan 15,4 ml volume air untuk membersihkan sediaan krim tabir surya pada bagian telapak tangan, sedangkan pada F1 membutuhkan 16,4 ml volume air untuk membersihkan sediaan krim tabir surya pada bagian telapak tangan dan F2 membutuhkan 17,4 ml volume air untuk membersihkan sediaan krim tabir surya pada bagian telapak tangan (Tabel 4).

Evaluasi uji daya menyebar diperoleh daya menyebar FB dengan range 11,039-10,458 cm2, F1 dengan range $8,292-7,789 \mathrm{~cm} 2$ dan $\mathrm{F} 2$ dengan range $8,038-7,789 \mathrm{~cm} 2$. Dilihat dari hasil uji daya menyebar FB lebih luas dari F1 dan F2, karena FB memberikan penyebaran yang lebih cepat dan luas. Daya menyebar sediaan krim akan berkaitan dengan kemudahan sediaan dioleskan di permukaan kulit. Semakin tinggi konsentrasi zat terdispersi (padat) di dalam sediaan akan semakin kecil kemampuan sediaan untuk menyebar.

Uji iritasi sediaan krim tabir surya dilakukan dengan 6 orang panelis pada tiap-tiap formula. Dilakukan pada lengan atas panelis dengan diameter $2 \mathrm{~cm}$ dan dibiarkan selama 24 jam. Dari pengujian terhadap semua panelis memperlihatkan tidak adanya terjadi iritasi pada kulit panelis, sehingga sediaan krim ekstrak etanol bekatul padi beras merah aman digunakan sebagai sediaan topikal.

Pada pemeriksaan stabilitas fisik sediaan krim tabir surya yang telah disimpan pada suhu kamar $\left(25^{\circ} \mathrm{C}\right.$ $\left.30^{\circ} \mathrm{C}\right)$ dan suhu dingin $\left(4^{\circ} \mathrm{C}\right)$ menunjukkan tidak terjadi 
pemisahan pada semua sediaan yang artinya sediaan

stabil selama penyimpanan.

Tabel 4. Rekapitulasi hasil evaluasi sediaan

\begin{tabular}{|c|c|c|c|c|c|c|c|c|}
\hline \multirow[b]{2}{*}{ Formula } & \multicolumn{8}{|c|}{ Evaluasi sediaan } \\
\hline & Organoleptis & Homogenitas & $\mathrm{pH}$ & $\begin{array}{l}\text { Daya } \\
\text { tercuci }\end{array}$ & $\begin{array}{c}\text { Uji } \\
\text { iritasi }\end{array}$ & $\begin{array}{c}\text { Daya } \\
\text { menyebar } \\
(5 \text { gram })\end{array}$ & $\begin{array}{l}\text { Stabilitas } \\
\text { (suhu } \\
\text { kamar) }\end{array}$ & $\begin{array}{c}\text { Stabilitas } \\
\text { (suhu } \\
\text { dingin) }\end{array}$ \\
\hline FB & $\begin{array}{c}\text { Bentuk : Semipadat } \\
\text { Warna : Putih } \\
\text { Bau : Khas }\end{array}$ & Homogen & 8,0 & $15,4 \mathrm{ml}$ & $\mathrm{Ti}$ & $11,04 \mathrm{~cm}^{2}$ & Stabil & Stabil \\
\hline F1 & $\begin{array}{c}\text { Bentuk : Semipadat } \\
\text { Warna : Coklat muda } \\
\text { Bau : Khas }\end{array}$ & Homogen & 6,5 & $16,4 \mathrm{ml}$ & $\mathrm{Ti}$ & $8,29 \mathrm{~cm}^{2}$ & Stabil & Stabil \\
\hline $\mathrm{F} 2$ & $\begin{array}{c}\text { Bentuk : Semipadat } \\
\text { Warna : Coklat tua } \\
\text { Bau : Khas }\end{array}$ & Homogen & 5,8 & $17,4 \mathrm{ml}$ & $\mathrm{Ti}$ & $8,03 \mathrm{~cm}^{2}$ & Stabil & Stabil \\
\hline
\end{tabular}

Keterangan $: \mathrm{Ti}=$ Tidak iritasi

Tabel 5. Nilai SPF FB, F1 dan F2 pada minggu ke-1 dan minggu ke-10

\begin{tabular}{|c|c|c|c|c|c|c|c|c|c|c|}
\hline \multicolumn{11}{|c|}{ Minggu ke-1 } \\
\hline & & & FB & & & $\mathrm{F} 1$ & & & $\mathrm{~F} 2$ & \\
\hline$\lambda(\mathrm{nm})$ & EExI & Abs & EExIxAbs & SPF & Abs & EExIxAbs & SPF & Abs & EExIxAbs & SPF \\
\hline 290 & 0,0150 & 0,735 & 0,0110 & \multirow{8}{*}{3,137} & 1,560 & 0,0234 & \multirow{8}{*}{11,861} & 1,768 & 0,0265 & \multirow{8}{*}{13,098} \\
\hline 295 & 0,0817 & 0,601 & 0,0491 & & 1,420 & 0,1160 & & 1,579 & 0,1290 & \\
\hline 300 & 0,2874 & 0,366 & 0,1051 & & 1,230 & 0,3535 & & 1,361 & 0,3911 & \\
\hline 305 & 0,3278 & 0,264 & 0,0865 & & 1,146 & 0,3756 & & 1,262 & 0,4136 & \\
\hline 310 & 0,1864 & 0,222 & 0,0413 & & 1,117 & 0,2082 & & 1,217 & 0,2268 & \\
\hline 315 & 0,0839 & 0,203 & 0,0170 & & 1,081 & 0,0906 & & 1,205 & 0,1010 & \\
\hline \multirow[t]{2}{*}{320} & 0,0180 & 0,195 & 0,0035 & & 1,030 & 0,0185 & & 1,198 & 0,0215 & \\
\hline & & & $\Sigma=0,3137$ & & \multicolumn{2}{|r|}{$\Sigma=1,1861$} & & \multicolumn{2}{|r|}{$\Sigma=1,3098$} & \\
\hline \multicolumn{11}{|c|}{ Minggu ke-10 } \\
\hline & & & FB & & & F1 & & & $\mathrm{F} 2$ & \\
\hline$\lambda(\mathrm{nm})$ & EExI & Abs & EExIxAbs & SPF & Abs & EExIxAbs & SPF & Abs & EExIxAbs & SPF \\
\hline 290 & 0,0150 & 0,730 & 0,0109 & \multirow{8}{*}{3,123} & 1,555 & 0,0233 & \multirow{8}{*}{11,845} & 1,765 & 0,0264 & \multirow{8}{*}{13,092} \\
\hline 295 & 0,0817 & 0,600 & 0,0490 & & 1,420 & 0,1160 & & 1,575 & 0,1286 & \\
\hline 300 & 0,2874 & 0,365 & 0,1049 & & 1,228 & 0,3529 & & 1,361 & 0,3911 & \\
\hline 305 & 0,3278 & 0,263 & 0,0862 & & 1,145 & 0,3753 & & 1,262 & 0,4136 & \\
\hline 310 & 0,1864 & 0,220 & 0,0410 & & 1,115 & 0,2078 & & 1,216 & 0,2266 & \\
\hline 315 & 0,0839 & 0,200 & 0,0167 & & 1,080 & 0,0906 & & 1,205 & 0,1010 & \\
\hline \multirow[t]{2}{*}{320} & 0,0180 & 0,193 & 0,0034 & & 1,030 & 0,0185 & & 1,195 & 0,0215 & \\
\hline & & & $\Sigma=0,3123$ & & & $\Sigma=1,1845$ & & & $\Sigma=1,3092$ & \\
\hline
\end{tabular}

Secara alami kulit berusaha melindungi dirinya beserta organ di bawahnya dari bahaya sinar UV B selama 10 menit. Pengujian nilai SPF pada ekstrak etanol bekatul padi beras merah menunjukkan nilai SPF pada konsentrasi 5\% adalah 2,231 dan konsentrasi $10 \%$ adalah 4,449 . Sementara nilai SPF sediaan FB adalah SPF 3,137 dalam kategori nilai SPF minimal menunjukkan bahwa basis krim mempunyai keefektifan sebagai tabir surya yang dapat melindungi kulit dari radiasi sinar UV B selama 30 menit. F1 mempunyai nilai SPF 11,861 dalam kategori nilai SPF maksimal menunjukkan bahwa F1 mempunyai keefektifan sebagai tabir surya yang dapat melindungi kulit dari radiasi sinar UV B selama 110 menit dan F2 mempunyai nilai SPF 13,098 dalam kategori nilai SPF maksimal menunjukkan bahwa F2 mempunyai keefektifan sebagai tabir surya yang dapat melindungi kulit dari radiasi sinar UV selama 130 menit (Rieger, 2000). 
Pada pengujian SPF pada minggu 10, FB, F1 dan F2 tidak menunjukkan penurunan yang bermakna terhadap nilai SPF masing-masing formula. Berdasarkan hasil tersebut menunjukkan bahwa nilai SPF stabil selama masa penyimpanan terlihat dari kecilnya perbedaan nilai SPF pada tiap-tiap formula sebelum dan selama masa penyimpanan (Tabel 5).

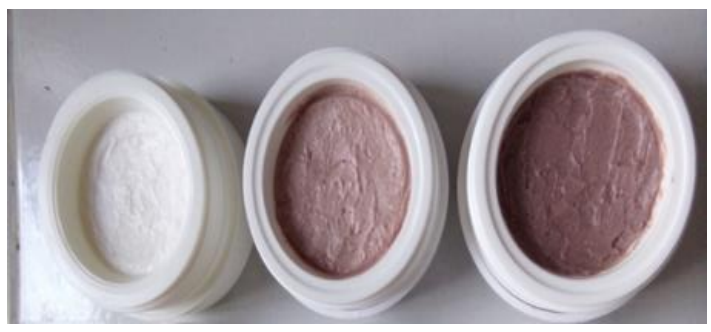

(a)

(b)

(c)

Gambar 2. Sediaan Krim Tabir Surya Ekstrak Etanol Bekatul Padi Beras Merah (Oryza sativa L), (a) FB, (b) F1, (c) F2

\section{KESIMPULAN}

Ekstrak etanol bekatul padi beras merah pada konsentrasi $5 \%\left(\mathrm{~F}_{1}\right)$ dan $10 \%\left(\mathrm{~F}_{2}\right)$ setelah diformulasi menjadi sediaan krim tabir surya memiliki nilai SPF yaitu 11,861 dan 13,098. Hasil ini menunjukkan bahwa sediaan krim tabir surya dari ekstrak etanol bekatul padi beras merah mempunyai keefektifan sebagai tabir surya yang dapat melindungi kulit dari radiasi sinar UV B selama 110-130. Semakin tinggi konsentrasi ekstrak etanol padi beras merah yang digunakan maka semakin meningkatkan nilai SPF pada formula.

\section{DAFTAR PUSTAKA}

Adzkiya, M.A.Z., 2011, Kajian Potensi Antioksidan Beras Merah Pemanfaatannya Pada Minuman Beras Kencur, Thesis, IPB.

Adi, W., Zulkarnain., A.K., 2015, Uji SPF In Vitro Dan Sifat Fisik Beberapa Produk Tabir Surya Yang Beredar Di Pasaran, Majalah Farmaseutik, 11 (1) : 275-283.

Ditjen POM., 1985, Formularium Kosmetika Indonesia, Departemen Kesehatan Republik Indonesia, Jakarta.

Chen, M. H., Bergman, CJ., 2005, A Rapid Procedure for Analysing Rice Bran Tocopherol, Tocotrienol and Gamma Oryzanol Contents, Journal of Food Composition and Analysis, 18 : 139-151.

Damogalad, V., Edy, H. J., Supriati, H. S., 2013, Formulasi Krim Tabir Surya Ekstrak Kulit Nanas (Ananas Comosus L Merr) Dan Uji In Vitro Nilai Sun Protecting Factor (SPF), Pharmacon Jurnal Ilmiah Farmasi - UNSRAT, 2 (2) : 39-45.

Hadipernata, M., 2007, Mengolah Dedak Menjadi Minyak (Rice Bran Oil), Warta Penelitian Dan Pengembangan Pertanian, 29 (4) : 8-10.

Jellinek, J., Stephan, D. R., 1970, Formulation and Function of Cosmetics, translated by G.L. Fenton., John Wiley \& Sons Inc, USA.

Mansur, J. S., Breder, M. N. R., Mansur, M. C. A., Azulay, R. D., 1986, Determinacao do fator de protecao solar por espectrofotometria, An, Bras, Dermatol, 61 : 121-124.

Rieger, M. 2000. Harry's Cosmeticology (8th Edition). New York: Chemical Publishing Co Inc

Sarastani, D., Suwarna, T., Soekarno, T. R., Muchtadi., Dedi, F., dan Anton, A., 2002, Aktivitas Antioksidan Ekstrak dan Fraksi Biji Atung, Jurnal Teknologi dan Industri Pangan, 13 (2) : 149-156.

Suhery, W.N. and Husni, D.N., 2017. Effect of cream base types on the antioxidant activity of the cream preparation of red rice bran extract. Research Journal of Pharmaceutical Biological and Chemical Sciences, 8, pp.255-262.

Voigt, R., 1994, Buku Pelajaran Teknologi Farmasi, Edisi Kelima, Diterjemahkan Oleh Drs,Soendani Noerono, Gadjah Mada Universitas Press, Yogyakarta.

Wasitaatmadja, S.M., 1997, Penuntun Ilmu Kosmetik Medik, Universitas Indonesia, Jakarta.

Widarta, I. W. R. 2014. Aktivitas Antioksidan Ekstrak Bekatul Beras Merah Dalam Sistem Pangan Terhadap Oksidator Dan pemanasan Pada Berbagai PH, Jurnal Teknologi dan Industri Pangan.

Wood, C., Murphy, E., 2000, Sunscreen Efficacy, Glob, Cosmet, Ind Duluth, 167: 38-44. 